\title{
TENDÊNCIAS POLÍTICO- PEDAGÓGICAS DE EDUCAÇÃO AMBIENTAL EM UNIDADES DE CONSERVAÇÃO: O CASO DOS PARQUES ESTADUAIS DE SÃO PAULO
}

\author{
Lucas Milani Rodrigues $^{1}$ \\ Ligia Maria Barrios Campanhão² \\ Yara Rosa Bernardi ${ }^{3}$
}

Resumo: Diferentes tendências político-pedagógicas de Educação Ambiental foram desenvolvidas historicamente junto ao movimento ambientalista no Brasil. $O$ presente artigo identificou, por análise documental, quais dessas tendências embasam as ações educativas dos Parques Estaduais paulistas, ambientes propícios para processos educativos. Os resultados indicam uma predominância da abordagem conservacionista e uma presença mais discreta das abordagens crítica e pragmática. Portanto, a Educação Ambiental nos Parques se mostra conservadora, embora exiba elementos de tendência crítica, mas que não têm atingido as ações práticas. Esses resultados contribuem para a reflexão do modelo de Educação Ambiental a ser exercida nos Parques.

Palavras-chave: Educação Ambiental; Unidades de Conservação; Parques; Tendências Político-Pedagógicas.

${ }^{1}$ Gestor Ambiental pela Universidade de São Paulo (USP). Mestre em Ciências dos Recursos Florestais pela Escola Superior de Agricultura "Luiz de Queiroz" (ESALQ), Universidade de São Paulo (USP). Doutorando em Ciências da Engenharia Ambiental pela EESC/USP. E-mail: milani.lucas@usp.br

2 Bióloga pela Universidade de São Paulo (USP). Mestre em Ciências da Engenharia Ambiental pela Escola de Engenharia de São Carlos (EESC), Universidade de São Paulo (USP). Doutoranda em Ciências da Engenharia Ambiental pela EESC/USP. E-mail: ligiambc@usp.br

${ }^{3}$ Engenheira Ambiental pela Universidade Federal do Triangulo Mineiro (UFTM). Mestranda em Ciências da Engenharia Ambiental pela EESC/USP.E-mail: yara_bernardi@usp.br 


\section{Introdução}

$\mathrm{Na}$ segunda metade do século passado, preocupações ambientais eclodiram de forma mais sistêmica nas sociedades, juntamente com 0 movimento de contracultura, quando discussões políticas mundiais passaram a considerar esse aspecto que havia sido negligenciado durante os séculos passados de exploração. Esta nova perspectiva trazida à discussão exigiu uma demanda por novos conhecimentos e uma postura em relação ao meio natural, o que inclui a disciplina de Educação Ambiental.

Nos primórdios do desenvolvimento da Educação Ambiental, destaca-se o trabalho de Stapp (1969), contemporâneo do livro "Primavera Silenciosa" publicado em 1962 por Rachel Carson, o qual teve grande impacto na inserção de questões ambientais na pauta do desenvolvimento. Segundo Stapp (1969, p.31, tradução nossa), a Educação Ambiental tem o objetivo de "(...) Produzir uma cidadania conhecedora do ambiente biofísico e seus problemas associados, consciente de como ajudar a solucionar esses problemas e motivada a trabalhar em direção à sua solução". O autor destaca que a população naquela época sofria com a poluição e a não compreensão da necessidade de planejamento ambiental e organização institucional para lidar com esses problemas. Ainda, a migração do homem do campo para a cidade fez com que se perdesse a consciência acerca da origem dos recursos naturais. Nesse sentido, a urbanização da sociedade era a causa direta da desconsideração da questão ambiental e, consequente, aumento dos impactos ambientais. Portanto, para o autor, a Educação Ambiental teria como objetivos principais a compreensão de que o homem faz parte de um sistema cultural e ambiental, a percepção dos aspectos biofísicos do ambiente e do ambiente "feito pelo homem" e o entendimento dos problemas causados aos ambientes biofísicos, visando resolvê-los. Assim, a resolução dos problemas ambientais só seria possível por meio de dados sobre o ambiente físico, os quais poderiam trazer o desenvolvimento de conceitos de qualidade ambiental. A partir dessa qualificação, as atitudes dos cidadãos poderiam vir a ser efetivas para a melhoria do ambiente (STAPP, 1969).

Posteriormente, outras definições acerca da Educação Ambiental emergiram, pois percebeu-se que essa disciplina envolvia outros aspectos (LAYRARGUES; LIMA, 2014). E preciso eliminar a ideia errônea sobre uma Educação Ambiental homogênea, pois se trata de um campo muito mais amplo (BERTOLUCCl et al. 2005). No Brasil, esse campo foi instituído a partir das décadas de 1970 e 1980, sendo que o contexto histórico dos anos seguintes determinou o perfil que a Educação Ambiental foi assumindo (LIMA, 2009).

De acordo com Sorrentino (1997), a Educação Ambiental pode ser classificada em quatro abordagens: Conservacionista, Educação ao ar livre, Gestão ambiental e Economia Ecológica. A primeira, conservacionista, aborda a questão dos impactos sobre a natureza causados pelo modelo de vida vigente. A segunda, educação ao ar livre, sempre teve como adeptos naturalistas, escoteiros, grupos de caminhadas, dentre outros. Posteriormente, essa linha ganhou um viés educacional com o uso de trilhas interpretativas

revista brasileira educação ambiental 
educacionais em ambientes naturais ou caminhadas com o intuito de sensibilizar os participantes. A terceira linha, gestão ambiental, se pauta na resistência a um sistema proliferador de mazelas ambientais, buscando espaços de participação da sociedade em decisões públicas relativas ao meio ambiente. Por fim, a quarta corrente, economia ecológica, divide-se em duas vertentes. Na primeira, chamada de "desenvolvimento sustentável", encontramse empresários, governantes e algumas ONGs que buscam adaptar-se às formas de organização social vigente, incorporando as questões ambientais. A segunda, denominada "sociedades sustentáveis", é formada pelos representantes que sempre se opuseram ao modelo econômico atualmente estabelecido. Sua aspiração é repensar o formato social estabelecido, incorporando valores como justiça e ambiente ecologicamente equilibrado. A corrente "sociedades sustentáveis" afirma que a vertente "desenvolvimento sustentável" não é nova, apenas outra abordagem que mantém o padrão do modelo econômico estabelecido (SORRENTINO, 1997).

Sauvé (2005) enxerga a Educação Ambiental partilhada em 15 correntes. Para essa categorização, foram considerados como critérios: a concepção dominante de meio ambiente, a intenção central da Educação Ambiental e os enfoques que são privilegiados nas abordagens. A autora ressalva que esta sistematização tem a intenção de ser uma ferramenta de análise das diferentes propostas educacionais e não uma tentativa de impor um segmento rígido de correntes de pensamento. Dentre as concepções de Educação Ambiental verificadas pela autora, há aquelas focadas no meio ambiente como natureza e fonte de recursos, aquelas que consideram a dimensão sociocultural do ambiente e também correntes voltadas para contribuir para o desenvolvimento econômico sustentável.

Ainda sobre o processo de sistematização de abordagens pedagógicas, Souza e Salvi (2012) verificaram que há um complexo quadro de influências e definições da Educação Ambiental desenvolvida no Brasil. Segundo as autoras, as propostas educativas se diferenciam entre suas matrizes políticopedagógicas; a relação do homem com a natureza que é abordada; qual a função social que a Educação Ambiental pode desempenhar; a forma de organização do conhecimento, no caso ciências humanas ou naturais; se possuem concepção antropocêntrica, naturalista ou globalizante; e se seus objetivos são políticos, econômicos, espirituais/culturais ou biológicos. Tal sistematização proporciona uma elucidação das diferentes abordagens e seus tópicos comuns e díspares, o que denota a profundidade que esta área de estudo alcançou ao longo dos anos.

Layrargues e Lima (2014) enxergam três macrotendências que permeiam a Educação Ambiental brasileira, sendo duas conservadoras e uma alternativa. As conservadoras, chamadas conservacionista e pragmática, não pressupõem o questionamento da estrutura social vigente, enquanto que a alternativa é chamada de tendência crítica (LAYRARGUES; LIMA, 2014).

A corrente Conservacionista está ligada aos princípios da Ecologia, por meio de uma valorização do afeto para com a natureza que, Revbea, São Paulo, V. 13, No 1: 192-212, 2018. 
consequentemente, levaria a uma mudança de comportamento dos indivíduos. Essa linha de pensamento não agrega as dimensões sociais, políticas e culturais dos problemas ambientais, focando apenas em temas como biodiversidade, Unidades de Conservação (UCs), biomas, ecoturismo, dentre outros (LAYRARGUES; LIMA, 2014). Tal tendência é típica dos primórdios da Educação Ambiental, sendo caracterizada como tecnicista e apolítica, um reflexo do regime militar vigente no Brasil à época (LIMA, 2009).

A tendência Pragmática vê a Educação Ambiental como um meio para atingir o desenvolvimento sustentável (LAYRARGUES; LIMA, 2014), conceito este que dominava o quadro político na década de 1990 (LIMA, 2009). Essa tendência inclui a proposta de Educação para o Desenvolvimento Sustentável da UNESCO (LIMA, 2009). Caracteriza-se como uma abordagem de resultados, que atenda às demandas do mercado. As propostas de Educação Ambiental desta linha majoritariamente trabalham temas como mecanismos de desenvolvimento limpo e ecoeficiência produtiva, exibindo uma preocupação com a geração crescente de resíduos sólidos. Esta linha difere da Conservacionista por não estar atrelada aos aspectos exclusivamente biológicos, mas também a uma preocupação mercadológica e tecnológica. Esta macrotendência é condizente com a organização social de exploração estabelecida, sem propor grandes embates a esta prerrogativa, exibindo apenas uma orientação em otimizar processos em vez de questioná-los (LAYRARGUES; LIMA, 2014).

Finalmente, a tendência Crítica se fundamenta a partir das mudanças históricas e sociopolíticas decorrentes da redemocratização a partir de 1980, tais como a ampliação do debate ambiental e a aproximação entre os setores dos movimentos sociais e ambientalistas (LIMA, 2009). Essa tendência representa a aplicação dos ideais democráticos e emancipatórios do pensamento crítico na educação (BERTOLUCCI et al., 2005) e visa discutir os mecanismos de dominação humana pela acumulação de capital, sendo oposta ao conservadorismo das duas linhas anteriores, que são condescendentes com o neoliberalismo. O diferencial da tendência crítica é o fato de ter como impulsionadores a problematização e a politização das questões ambientais, não se atendo apenas aos aspectos biológicos ou de melhoria da ecoeficiência. Em seu escopo há a necessidade de enfrentamento político das desigualdades e injustiças socioambientais. Outro ponto de destaque da tendência crítica é a complexidade com que as questões ambientais são abordadas, indo contra o reducionismo da ação individual em prol de um bem comum. Esta linha compreende que as questões ambientais emergentes possuem diferentes faces de poder e dominação e que, para que se possa construir um conhecimento transformador, o reducionismo não pode ser premissa (LAYRARGUES; LIMA, 2014).

Após muitos avanços na compreensão da problemática ambiental, assim como na evolução das proposições sobre Educação Ambiental, em 1999 foi sancionada no Brasil a Política Nacional de Educação Ambiental (PNEA), que dá a seguinte definição (BRASIL, 1999, Art. 1º):

revista brasileira educação ambiental 
Entende-se por Educação Ambiental os processos por meio dos quais o indivíduo e a coletividade constroem valores sociais, conhecimentos, habilidades, atitudes e competências voltadas para a conservação do meio ambiente, bem de uso comum do povo, essencial à sadia qualidade de vida e sua sustentabilidade.

O texto jurídico também afirma que a Educação Ambiental é um componente que deve ser inerente à educação nacional. Ao poder público fica incumbida a tarefa de traçar políticas públicas que incorporem essa dimensão ambiental, sendo um direito de toda a população o acesso a esse repertório educacional que promove o engajamento social na conservação, recuperação e melhoria do meio ambiente (BRASIL, 1999). Essas premissas estão alinhadas com o artigo 225 da Constituição Brasileira, que prevê a garantia de um ambiente equilibrado a toda população (BRASIL, 1988). É importante destacar que os princípios fundamentais da PNEA vão além dos aspectos biofísicos e consideram o enfoque humanista, holístico, plural, a necessidade de compreensão da interdependência entre aspectos socioeconômicos e culturais, a constante revisão dos processos pedagógicos implantados e uma orientação para a construção destes processos de forma contínua. Além disso, a PNEA visa garantir a democracia no acesso às informações ambientais, estimular o pensamento crítico, a participação individual e coletiva, a cooperação entre as diversas regiões do país, a integração da ciência e tecnologia neste processo, assim como uma ampliação cidadã do povo brasileiro em prol de uma sociedade solidária, justa socialmente, democrática, responsável e sustentável (BRASIL, 1999).

A Educação Ambiental no Brasil legalmente tem caráter formal e não formal. A educação não formal são aquelas "ações e práticas educativas voltadas à sensibilização da coletividade sobre as questões ambientais e à sua organização e participação na defesa da qualidade do meio ambiente" (BRASIL, 1999, Art. 13). Dentre os deveres do poder público no que diz respeito à educação não formal, destaca-se a incumbência de incentivar a sensibilização da sociedade perante as UCs (BRASIL, 1999), que são espaços territoriais especialmente protegidos instituídos pelo Sistema Nacional de Unidades de Conservação (SNUC) (Lei Federal no 9.985/2000). Dentre as diretrizes que regem o SNUC há a busca de parcerias para a realização de práticas de Educação Ambiental nas UCs (BRASIL, 2000). Dentre as categorias de espaços protegidos previstos pelo SNUC, destaca-se o Parque4, que tem como objetivo básico a preservação dos ecossistemas, focando em atividades como pesquisa científica, ecoturismo e Educação Ambiental. Portanto, trata-se de uma UC apta e que possui vocação para desenvolver essas atividades educativas (BRASIL, 2000).

4 "As unidades dessa categoria, quando criadas pelo Estado ou Município, serão denominadas, respectivamente, Parque Estadual e Parque Natural Municipal” (BRASIL, 2000 Art. 11§ 4ㅇ).

Revbea, São Paulo, V. 13, № 1: 192-212, 2018. 
No caso do estado de São Paulo, há 29 Parques Estaduais instituídos, o que corresponde a 767 mil hectares de área protegida, cerca de $3 \%$ do estado. A maioria se localiza na região litorânea e no Vale do Rio Ribeira (FUNDAÇÃO FLORESTAL, 2017b). Com relação à Educação Ambiental a ser desenvolvida nessas áreas, a Política Estadual de Educação Ambiental (PEEA) também agrega princípios congruentes com a Política Nacional e traz objetivos com elementos críticos, tais como: formar uma sociedade politicamente atuante e socialmente justa, participativa e com compreensão integrada do meio ambiente (SÃO PAULO, 2007). O texto legal também reforça a importância da participação e do acompanhamento da gestão das UCs, enfatizando métodos participativos, inclusivos, abrangentes e que valorizem a pluralidade cultural, saberes e especificidades sociais (SÃO PAULO, 2007). Mais especificamente, o órgão gestor destas áreas, a Fundação Florestal (FF), dispõe o direcionamento da Educação Ambiental a ser adotada nas UCs da seguinte forma (FUNDAÇÃO FLORESTAL, 2017a):

A Educação Ambiental nas Unidades de Conservação sob gestão da FF é entendida como um processo permanente no qual os indivíduos e a sociedade têm a oportunidade de vivenciar e conhecer estas áreas naturais protegidas, culminando em ações pró-ativas para a conservação da biodiversidade e das diversidades cultural e histórica nelas inseridas. É uma das estratégias na gestão e na consolidação destas unidades de conservação. Enquanto espaços educadores, as UCs são elo de integração com a sociedade, possibilitando o fortalecimento e o empoderamento da população, com potencialização da ação individual e coletiva. Por meio da experimentação direta, os visitantes utilizam todos os sentidos, vivenciam emoções e sensações, ao mesmo tempo que conhecem mais sobre a natureza e cultura das unidades e das populações do entorno.

Segundo as tendências apontadas por Layrargues e Lima (2014), este direcionamento tem muitos elementos da tendência conservacionista de Educação Ambiental, pois tem foco na conservação da biodiversidade por meio da sensibilização. Entretanto, também faz menção ao fortalecimento e empoderamento da população por meio da Educação Ambiental, que é característico da macrotendência crítica. Nesse sentido, constata-se que há um misto de orientações político-pedagógicas que permeiam as práticas de Educação Ambiental no Brasil. Isso se justifica pelo fato de a disciplina receber contribuições de diversas áreas do conhecimento, pela orientação legal a ser seguida e também pelas tendências historicamente dominantes que foram responsáveis por moldar o perfil da Educação Ambiental no país (LIMA, 2009). Atualmente, o mapeamento das correntes na Educação Ambiental praticada no Brasil é insuficiente (LAYRARGUES; LIMA, 2014), não havendo pesquisas que abranjam o território nacional (LIMA, 2009). Lima (2009) considera que a tendência crítica se expandiu e pode ser dominante, pelo menos no chamado 
"núcleo orientador", que é formado por atores que tem o poder de dar a orientação teórica, política e ideológica, ou seja, professores e educadores, pesquisadores e técnicos. Layrargues e Lima (2014) também partilham da ideia de expansão da tendência crítica, mas afirmam que ainda há grande influência da abordagem pragmática, dominante na opinião desses autores.

Este trabalho visa contribuir para suprir essa lacuna por meio do diagnóstico das linhas de pensamento que têm orientado as ações de Educação Ambiental não-formal no âmbito de espaços de responsabilidade do poder público. É preciso pesquisar o teor da Educação Ambiental realizada no Brasil de forma a contribuir com o aprimoramento desse processo (SOUZA; SALVI, 2012). Considerando a vocação dos Parques como ambiente propício e apto a essa prática pedagógica, o objetivo desta pesquisa é verificar quais tendências político-pedagógicas têm sido predominantemente usadas para embasar as ações de Educação Ambiental desenvolvida nessas UCs. Para isso adotou-se como universo de estudo os Parques Estaduais de São Paulo.

\section{Metodologia}

O delineamento metodológico utilizado para responder à pergunta deste estudo foi a pesquisa documental (GIL, 2011). Os documentos analisados foram os Planos de Manejo dos Parques de São Paulo, que se encontram disponíveis no sítio eletrônico da Fundação Florestal (http://fflorestal.sp.gov.br/). Embora haja cerca de 30 Parques Estaduais sob gestão da FF, apenas 16 possuem Plano de Manejo aprovados, os quais compuseram o conjunto de documentos analisados. Foi adotado o Plano de Manejo como fonte de dados visto que é o documento no qual todas as questões relativas ao uso e manejo dos recursos da UC devem estar dispostas, sendo que as ações de visitação devem ser compatíveis com o determinado no plano (BRASIL, 2000).

Para verificar o ajustamento das ações previstas nos Planos com as tendências de Educação Ambiental adotou-se a classificação de Layrargues e Lima (2014), que foi elaborada tendo em vista o histórico da Educação Ambiental brasileira. Essa classificação foi escolhida por ser um ensaio recente com vistas a compreender a dinâmica atual da Educação Ambiental no Brasil, onde os autores detalham as características e o substrato de cada tendência, sendo adequada para fins didáticos, analíticos e políticos (LAYRARGUES; LIMA, 2014).

A fim de direcionar a análise, foi elaborado um quadro contendo os elementos que caracterizam as tendências segundo Layrargues e Lima (2014). Para a construção do Quadro 1 foram usados critérios de classificação semelhantes aos empregados por Sauvé (2005), ou seja, qual a concepção de meio ambiente, o objetivo da Educação Ambiental e os temas privilegiados em cada corrente. As dimensões propostas no quadro indicam como cada linha de Educação Ambiental aborda a estrutura socioeconômica vigente e quais são as bases disciplinares, políticas, econômicas ou sociais nas quais as tendências Revbea, São Paulo, V. 13, № 1: 192-212, 2018. 
surgiram e/ou se suportam. Além disso, indica como a Educação Ambiental, como disciplina, é vista por cada uma das suas correntes, ou seja, qual seu papel ou objetivo final. Finalmente, o quadro ilustra como os problemas ambientais são vistos por cada uma dessas correntes, isto é, suas causas, consequências e soluções; os temas que são frequentes nessas correntes e quais atividades costumam ser executadas.

Quadro 1: Elementos que caracterizam as tendências político-pedagógicas de EA.

\begin{tabular}{|c|c|c|c|}
\hline & \multicolumn{3}{|c|}{ Tendência político-pedagógica } \\
\hline & Conservacionista & Pragmática & Crítica \\
\hline Dimensão & Conservadora & Conservadora & Alternativa \\
\hline $\begin{array}{l}\text { Visa questionar a } \\
\text { estrutura } \\
\text { socioeconômica } \\
\text { vigente? }\end{array}$ & Não & Não & Sim \\
\hline $\begin{array}{l}\text { Base disciplinar, } \\
\text { política, } \\
\text { econômica ou } \\
\text { social }\end{array}$ & $\begin{array}{l}\text {-Ciência ecológica; } \\
\text {-Não considera } \\
\text { dimensões sociais, } \\
\text { políticas e culturais. }\end{array}$ & $\begin{array}{l}\text {-Hegemonia neoliberal; } \\
\text {-Redução do estado; } \\
\text {-Pragmatismo } \\
\text { contemporâneo; } \\
\text {-Ecologismo de } \\
\text { mercado; } \\
\text {-Lógica de mercado } \\
\text { acima das esferas } \\
\text { sociais; } \\
\text {-Ambientalismo de } \\
\text { resultados; } \\
\text {-Contexto de produção } \\
\text { e consumo surgidos no } \\
\text { pós-guerra. }\end{array}$ & $\begin{array}{l}\text {-Correntes de educação } \\
\text { popular, emancipatória, } \\
\text { transformadora e } \\
\text { educação no processo } \\
\text { de gestão ambiental. }\end{array}$ \\
\hline $\begin{array}{l}\text { Objetivo/papel da } \\
\text { Educação } \\
\text { Ambiental }\end{array}$ & $\begin{array}{l}\text {-Sensibilizar; } \\
\text {-Despertar a } \\
\text { dimensão afetiva em } \\
\text { relação à natureza. }\end{array}$ & $\begin{array}{l}\text {-Empregada como } \\
\text { forma de compensação } \\
\text { para corrigir as } \\
\text { imperfeições de um } \\
\text { mercado baseado no } \\
\text { consumismo, } \\
\text { obsolescência } \\
\text { programada e } \\
\text { descartabilidade; } \\
\text {-Educação para } \\
\text { desenvolvimento/consu } \\
\text { mo sustentável. }\end{array}$ & $\begin{array}{l}\text {-Rever criticamente os } \\
\text { fundamentos que } \\
\text { condicionam a } \\
\text { dominação do ser } \\
\text { humano e dos } \\
\text { mecanismos de } \\
\text { acumulação do capital; } \\
\text {-Enfrentamento político } \\
\text { das desigualdades e } \\
\text { injustiça social; } \\
\text {-Contextualizar o debate } \\
\text { ambiental; } \\
\text {-Problematizar as } \\
\text { contradições dos } \\
\text { modelos de } \\
\text { desenvolvimento e } \\
\text { sociedade. }\end{array}$ \\
\hline
\end{tabular}

Continua... 


\begin{tabular}{|c|c|c|c|}
\hline & \multicolumn{3}{|c|}{ Tendência político-pedagógica } \\
\hline & Conservacionista & Pragmática & Crítica \\
\hline $\begin{array}{l}\text { Visão dos } \\
\text { problemas } \\
\text { ambientais }\end{array}$ & $\begin{array}{l}\text {-Redução dos } \\
\text { problemas ambientais } \\
\text { a uma questão com } \\
\text { solução por inovação } \\
\text { tecnológica; } \\
\text {-Acredita que os } \\
\text { princípios de mercado } \\
\text { são capazes de } \\
\text { promover transição } \\
\text { para sustentabilidade. }\end{array}$ & $\begin{array}{l}\text {-Redução dos } \\
\text { problemas ambientais a } \\
\text { uma questão com } \\
\text { solução por inovação } \\
\text { tecnológica; } \\
\text {-Dissociados das } \\
\text { dimensões social e } \\
\text { econômica; } \\
\text {-Sem reflexão } \\
\text { contextual e articulada } \\
\text { das causas e } \\
\text { consequências dos } \\
\text { problemas ambientais. }\end{array}$ & $\begin{array}{l}\text {-Os problemas } \\
\text { ambientais não têm } \\
\text { solução reducionista; } \\
\text { - Os problemas } \\
\text { ambientais têm causas e } \\
\text { consequências em } \\
\text { esferas sociais e políticas } \\
\text { além da biológica. }\end{array}$ \\
\hline Temas e ações & $\begin{array}{l}\text {-Autoconhecimento; } \\
\text {-Atividades ao ar } \\
\text { livre; } \\
\text {-Biodiversidade; } \\
\text {-Unidades de } \\
\text { Conservação; } \\
\text {-Biomas; } \\
\text {-Ecoturismo; } \\
\text {-Experiências } \\
\text { agroecológicas; } \\
\text {-Mudanças culturais } \\
\text { relevantes, mas } \\
\text { que só podem ser } \\
\text { concretizadas se } \\
\text { houver a } \\
\text { transformação das } \\
\text { bases econômicas } \\
\text { e políticas da } \\
\text { sociedade. }\end{array}$ & $\begin{array}{l}\text {-Economia e consumo verde; } \\
\text {-Responsabilidade } \\
\text { socioambiental; } \\
\text {-Certificação; } \\
\text {-Mecanismos de } \\
\text { desenvolvimento limpo; } \\
\text {-Responsabilização individual } \\
\text { ("cada um fazer a sua parte"); } \\
\text {-Afastamento do ambiente } \\
\text { natural; } \\
\text {-Foco no ambiente urbano- } \\
\text { industrial; } \\
\text {-Preocupação com produção } \\
\text { de resíduos sólidos; } \\
\text {-Ações que tragam resultados } \\
\text { orientados para a } \\
\text { sustentabilidade, mas dentro } \\
\text { de um realismo político, do } \\
\text { economicamente viável e da } \\
\text { conservação do status quo. }\end{array}$ & $\begin{array}{l}\text {-Conceitos } \\
\text { introduzidos no } \\
\text { debate: Cidadania, } \\
\text { Democracia, } \\
\text { Participação, } \\
\text { Emancipação, } \\
\text { Conflito, Justiça } \\
\text { Ambiental e } \\
\text { Transformação } \\
\text { Social. }\end{array}$ \\
\hline
\end{tabular}

Fonte: elaborado pelos autores a partir de Layrargues e Lima (2014).

*Aqui se considera a gestão ambiental como prevalentemente política, em vez de somente uma disciplina de caráter administrativo

Os Planos de Manejo foram submetidos a uma análise inicial para detectar os tópicos do documento que contemplavam o programa de Educação Ambiental praticado ou a ser praticado pelas Unidades. As informações acerca desse programa foram comumente encontradas no tópico "Programas de Gestão", mais especificamente na seção direcionada ao "Uso público" do Parque. Assim, para a coleta de dados, foram lidas informações sobre o diagnóstico das ações atuais no Parque, as ações planejadas, os objetivos do programa e as diretrizes. Diante desse conteúdo, as informações localizadas foram contrapostas ao Quadro 1 de forma a identificar elementos compatíveis com uma das três tendências político-pedagógicas de Educação Ambiental adotadas neste trabalho.

Revbea, São Paulo, V. 13, № 1: 192-212, 2018. 
O método descrito foi aplicado em duas etapas: primeiro cada documento foi lido individualmente por cada autor, e em seguida foi realizada a leitura conjunta de forma a classificar as tendências de cada Plano. Os resultados são apresentados na próxima seção e são discutidos de acordo com as publicações de autores do campo da Educação Ambiental.

\section{Resultados e discussão}

Após a avaliação dos programas de Educação Ambiental descritos nos Planos de Manejo, os resultados foram sintetizados no Quadro 2, onde estão apontadas quais tendências foram identificadas em cada Parque.

Quadro 2: Tendências político-pedagógicas de Educação Ambiental nos Parques Estaduais Paulistas.

\begin{tabular}{|c|c|c|c|}
\hline Parque Estadual (PE) & $\begin{array}{c}\text { Tendência } \\
\text { Conservacionista }\end{array}$ & $\begin{array}{l}\text { Tendência } \\
\text { Pragmática }\end{array}$ & $\begin{array}{c}\text { Tendência } \\
\text { Crítica }\end{array}$ \\
\hline Aguapeí & $\mathrm{X}$ & & \\
\hline Campina do Encantado & $\mathrm{X}$ & $\mathrm{X}$ & $\mathrm{X}$ \\
\hline Campos do Jordão & $x$ & $x$ & \\
\hline Cantareira & $X$ & $x$ & $\mathrm{X}$ \\
\hline Carlos Botelho & $\mathrm{X}$ & & \\
\hline Ilha do Cardoso & $\mathrm{X}$ & & $\mathrm{X}$ \\
\hline Ilhabela & $\mathrm{X}$ & $\mathrm{X}$ & $\mathrm{X}$ \\
\hline Intervales & $\mathrm{X}$ & & $\mathrm{X}$ \\
\hline Jaraguá & $x$ & $\mathrm{X}$ & $\mathrm{X}$ \\
\hline Jurupará & $\mathrm{X}$ & & $\mathrm{X}$ \\
\hline Mananciais de Campos do Jordão & $\mathrm{X}$ & $\mathrm{X}$ & \\
\hline Morro do Diabo & $X$ & $\mathrm{X}$ & \\
\hline Porto Ferreira & $X$ & & \\
\hline Rio do Peixe & $\mathrm{X}$ & & \\
\hline Serra do Mar & $X$ & $\mathrm{X}$ & $\mathrm{X}$ \\
\hline Xixová-Japui & $X$ & $\mathrm{X}$ & \\
\hline TOTAL (\% da amostra) & $16(100 \%)$ & $9(56,25 \%)$ & $8(50 \%)$ \\
\hline
\end{tabular}

Como pode ser observado pelos resultados obtidos (Quadro 2), todos os Planos de Manejo analisados apresentaram elementos da macrotendência conservacionista em suas ações de Educação Ambiental, 56,25\% apresentaram elementos da tendência pragmática e $50 \%$ apresentaram elementos da tendência crítica. Sete Parques apresentaram duas tendências diferentes, cinco apresentaram todas as três, e quatro exibiram apenas uma tendência. Para os Parques que apresentaram duas tendências diferentes, quatro deles empregaram a pragmática e três empregaram a crítica, além da conservacionista.

Especificamente para o universo dos Parques Estaduais paulistas, os resultados discordam das afirmações de Lima (2009) e Layrargues e Lima 
(2014), que cogitaram, respectivamente, a pragmática e a crítica como tendências dominantes. No entanto, os resultados do presente trabalho vão ao encontro dos obtidos por Dias (2015) que, ao analisar teses e dissertações tratando de práticas pedagógicas de Educação Ambiental em UCs, verificou uma dominância da tendência conservacionista como orientadora dessas ações. Por outro lado, ao analisar uma amostra majoritariamente de UCs federais (>80\%), Valenti et al. (2012) verificaram que a linha pedagógica dominante foi a "educação no processo da gestão ambiental", considerada crítica por Layrargues e Lima (2014). Uma justificativa possível para esse resultado é o esforço feito pelo Instituto Brasileiro do Meio Ambiente e dos Recursos Naturais Renováveis (Ibama) em reestruturar a Educação Ambiental nas UCs, o que inclui a divulgação dessa corrente nessas áreas protegidas (VALENTI et al., 2012). Embora haja predominância da tendência conservacionista nos programas de Educação Ambiental dos Planos de Manejo dos Parques, os resultados indicam que há uma expansão da corrente crítica, ou seja, cada vez mais os Parques têm agregado elementos dessa tendência, conforme cogitado por Lima (2009), Valenti et al. (2012), Layrargues e Lima (2014) e Dias (2015). Isso indica que a tendência crítica está tendo espaço e sendo capaz de concorrer com os outros discursos de educação no âmbito do seu núcleo orientador (LIMA, 2009). Entretanto, segundo Dias (2015), a tendência crítica tem sido mais frequentemente usada pelas UCs de Uso Sustentável, enquanto que as UCs de Proteção Integral se atêm mais às orientações conservadoras ${ }^{5}$.

A prevalência da corrente conservacionista também era esperada por Dias (2015), visto que as UCs, em especial as de Proteção Integral, visam à preservação de ecossistemas naturais livres de intervenção humana, permitindo apenas o uso indireto. Ainda, no caso dos Parques, seu objetivo destaca o foco em atividades de recreação e turismo ecológico. Portanto, era esperada uma dominância de elementos da ciência ecológica, foco na dimensão afetiva do ambiente e atividades relativas à conservação da biodiversidade, especialmente porque essa tendência é vista como forte e bem consolidada, notadamente em UCs (LAYRARGUES; LIMA, 2014). Além disso, o resultado encontrado pode ser um reflexo do disposto no Plano Estratégico Nacional de Áreas Protegidas (BRASIL, 2006), onde a concepção de Educação Ambiental ainda é conservadora e conservacionista (LOUREIRO; CUNHA, 2008).

Os Planos com viés conservacionista se destacaram por apresentar a Educação Ambiental como uma forma de despertar a dimensão afetiva com relação ao ambiente, sendo que a sensibilização das pessoas para a importância de conservar as UCs, os recursos naturais, a biodiversidade e os serviços ambientais foi amplamente citada como um objetivo, assim como a valorização dos mesmos (FUNDAÇÃO FLORESTAL, 2001, 2003, 2006, 2008a, 2008b, 2008c, 2009a, 2009b, 2009c, 2010a, 2010b, 2010c, 2010d, 2015a,

${ }^{5}$ Os Parques estão enquadrados como UCs de Proteção Integral (BRASIL, 2000).

Revbea, São Paulo, V. 13, № 1: 192-212, 2018. 
2015b, 2015c). Portanto, pode-se inferir que os Planos ainda adotam uma postura majoritariamente conservadora perante a Educação Ambiental, refletindo a influência de uma concepção arraigada ao quadro político autoritário dos primórdios da Educação Ambiental no Brasil (LIMA, 2009).

Um discurso bem frequente no texto dos Planos de Manejo foi o papel da Educação Ambiental em disseminar conhecimento, mobilizar e formar pessoas de modo que se tornem atuantes na conservação da UC, mudando seu comportamento e se responsabilizando pela conservação. Os Planos de Manejo dos Parques Campos do Jordão (FUNDAÇÃO FLORESTAL, 2015a) e Jurupará (FUNDAÇÃO FLORESTAL, 2010c) utilizaram a expressão "conhecer para preservar". Essa postura prega a responsabilização individual pelos problemas ambientais, em vez de abordar o caráter coletivo, público e político, o que revela a influência da concepção neoliberal da crise ambiental (LIMA, 2009). A necessidade de sensibilização das pessoas assume que os problemas ambientais são consequência da falta de informação e insensibilidade dos indivíduos acerca da dinâmica ecossistêmica e seu papel essencial no suporte à vida humana. Ao proporcionar conhecimento aos indivíduos, os comportamentos seriam alterados levando à militância a favor do meio ambiente, o que solucionaria os problemas ambientais (LIMA, 2009). Essa adequação do comportamento é um discurso muito influente nas atividades de Educação Ambiental das UCs (LOUREIRO; CUNHA, 2008).

Diante desses objetivos de sensibilizar e informar as pessoas visando à conservação, os Planos basicamente elencaram como ações e temas tratados: palestras, coleta de lixo, plantio de mudas, visita a museu, lazer e recreação ao ar livre, ecoturismo, trilhas, interpretação ambiental e autoconhecimento, que são comuns na abordagem conservacionista (LAYRARGUES; LIMA, 2014). Algumas dessas ações (e.g. coleta de resíduos e plantio de árvores) deixam transparecer a preocupação excessiva com as consequências dos problemas ambientais, por meio da prescrição de soluções tecnológicas para atenuá-las, em vez do questionamento das causas (LIMA, 2009). Portanto, há um destaque para essas práticas que são relevantes, mas que não tem impacto real quando desvinculadas do questionamento sobre as dimensões sociais, políticas e culturais que se inter-relacionam com os problemas ambientais (LAYRARGUES; LIMA, 2014).

Na prática, a visão da Educação Ambiental com caráter conservacionista e de mudança de comportamento é bastante difundida entre os atores responsáveis pelas ações executadas nas UCs, conforme verificado pelas entrevistas feitas por Wick e Silva (2015) com monitores de Educação Ambiental, coordenadores de uso público e gestores dos Parques Estaduais Cantareira, Jaraguá e Serra do Mar. Os resultados do referido trabalho indicam que esses atores enxergam o papel da Educação Ambiental na UC majoritariamente com caráter de: conscientização, conservação, preservação, mudança de comportamento, sensibilização e experiência estética. Para os autores, à Educação Ambiental tem sido atribuído o papel de resolver os problemas ambientais das UCs, conforme alguns gestores corroboraram ao 
afirmar que o objetivo da Educação Ambiental no Parque era transmitir conhecimentos aos visitantes ou sensibilizá-los sobre a importância de mantêlo preservado (WICK; SILVA, 2015).

Os programas de Educação Ambiental exclusivamente conservacionistas foram os dos Parques Estaduais do Aguapeí, Carlos Botelho, Porto Ferreira e Rio do Peixe. Esses Parques focaram somente no papel da Educação Ambiental como mecanismo de sensibilização, enfatizando atividades de turismo e recreação e aquelas relativas a diminuir o nível de degradação ou aumentar a proteção da própria UC (FUNDAÇÃO FLORESTAL, 2003, 2008b, 2009c, 2010a).

Os Planos que também apresentaram elementos da corrente pragmática enfatizaram o papel da Educação Ambiental como forma de promover ou viabilizar o desenvolvimento sustentável. Nesse sentido, foram abordadas questões como: incentivar o consumo sustentável, formação de jovens líderes para a construção de um modelo de desenvolvimento sustentável, desenvolvimento de negócios sustentáveis, responsabilização pela geração e aproveitamento de resíduos, orientar a implantação de novas tecnologias sociais focadas na cultura da sustentabilidade, buscar alternativas econômicas de desenvolvimento socioambiental sustentável das comunidades, dentre outras (FUNDAÇÃO FLORESTAL, 2006, 2008a, 2008c, 2009a, 2010b, 2010d, 2015a, 2015b, 2015c).

Nesse caso, ainda há ausência de reflexão contextual das causas e consequências da crise ambiental. A lógica de mercado se sobrepõe à dimensão social do ambiente, em um contexto que ignora a desigualdade e a injustiça. As ações enfatizadas estão alinhadas com um futuro sustentável, conforme é verificado pela preocupação em formar pessoas e desenvolver novas tecnologias para propagar a ideia de desenvolvimento sustentável. Entretanto, essas ações são coniventes com o status quo, ou seja, são compatíveis com os limites do politicamente aceito e do economicamente viável. Portanto, essa tendência assume que os problemas ambientais são um produto inevitável do capitalismo, colocando a Educação Ambiental como meio para compensar essa falha no sistema (LAYRARGUES, LIMA, 2014).

Os Planos que incluíram a macrotendência de Educação Ambiental crítica foram assim classificados por apresentarem alguns dos elementos que se aproximam das ideias defendidas por esta corrente. A linha crítica assume que aspectos ecológicos, políticos e sociais da crise ambiental são indissociáveis (LIMA, 2009). Nesse sentido, conceitos como cidadania, democracia, participação, emancipação, conflito, justiça ambiental e transformação passam a ser considerados (LAYRARGUES; LIMA, 2014). Alguns Planos de Manejo dos Parques Estaduais, como os de Campina do Encantado (FUNDAÇÃO FLORESTAL, 2008a) e Ilhabela (FUNDAÇÃO FLORESTAL, 2015c) destacaram a importância da aproximação e envolvimento com as comunidades tradicionais, de modo que as ações educativas se aproximem de sua realidade, gerando uma fonte alternativa de renda, mas também de forma a contribuir com a formação de pessoas mais Revbea, São Paulo, V. 13, № 1: 192-212, 2018. 
críticas e engajadas. O Parque Estadual llha do Cardoso considera que a Educação Ambiental é uma via para a resolução de conflitos entre a comunidade do entorno e a UC, trazendo conceitos de participação e democracia (FUNDAÇÃO FLORESTAL, 2001). O Parque Estadual da Serra do Mar destaca a importância de projetos de Educação Ambiental voltados para a cidadania, pautados em princípios sustentáveis e de justiça social (FUNDAÇÃO FLORESTAL, 2008c). De fato, Dias (2015) destaca que a tendência políticopedagógica crítica nas UCs tem se preocupado especialmente com investigar a realidade do público envolvido, o contexto de implantação do espaço protegido, como ele afetou as comunidades do entorno e sondar eventuais conflitos desses atores com a área.

Outros Planos de Manejo trazem elementos da tendência crítica que mais se aproximam da ideia central defendida por Layrargues e Lima (2014), ou seja, de uma Educação Ambiental questionadora da estrutura socioeconômica vigente, que contextualiza os problemas ambientais nas esferas sociais e políticas de forma a problematizar as definições atuais de desenvolvimento e sociedade. São exemplos os Parques Estaduais Cantareira, Intervales, Jaraguá e Jurupará (FUNDAÇÃO FLORESTAL, 2009a, 2009b, 2010b, 2010c).

O Plano de Manejo do Parque Estadual Jaraguá tem em suas diretrizes uma preocupação com 0 aprimoramento das atividades de Educação Ambiental, destacando qual deve ser o seu objetivo (FUNDAÇÃO FLORESTAL, 2010b, p. 334):

O desenvolvimento de uma compreensão integrada do meio ambiente em suas múltiplas e complexas relações; o estímulo e o fortalecimento de uma consciência crítica sobre a problemática ambiental e social e o incentivo à participação individual e coletiva, permanente e responsável, na preservação do equilíbrio do meio ambiente.

O Plano de Manejo do Parque Estadual Cantareira expressa preocupação com a necessidade de desenvolver uma educação crítica no futuro quando define que "um programa de educação e meio ambiente deve promover, prioritariamente, a atividade de reflexão sobre as relações socioeconômicas e culturais entre a sociedade e a natureza e o desenvolvimento de atitudes" (FUNDAÇÃO FLORESTAL, 2009a, p. 397).

O Plano de Manejo do Parque Estadual Intervales reconhece o potencial da Unidade em trabalhar concepções mais críticas. Nesse sentido, destaca que suas práticas educativas devem ser pautadas no "combate à pobreza, na equidade e justiça social, na sustentabilidade ecológica e cultural das comunidades vizinhas" (FUNDAÇÃO FLORESTAL, 2009b, p. 959). Além disso, o Plano também define como princípio "Contribuir para a criação de uma filosofia voltada para a formação do homem integral, cósmico, reflexivo, 
participativo voltado para o desenvolvimento de novos paradigmas, por uma sociedade sustentável e para cultura da paz" (FUNDAÇÃO FLORESTAL, 2009b, p. 960).

Por fim, o Plano de Manejo do Parque Estadual Jurupará enfatiza que a Educação Ambiental só tem efeito quando feita em um processo contínuo e em longo prazo, deixando claro que "As mudanças de atitude para com o meio ambiente e a sociedade estão associadas às condições de dignidade da existência humana e à mudança na lógica econômica instalada" (FUNDAÇÃO FLORESTAL, 2010c, p. 390). Nesse sentido, este Plano destaca a premissa de que os problemas ambientais não têm solução reducionista (LAYRARGUES; LIMA, 2014).

Embora os Planos de Manejo dessas áreas protegidas demonstrem uma sintonia com a tendência crítica de acordo com o referencial teórico utilizado, pode haver uma incongruência entre este e as ações que são executadas na prática (AVANZI et al., 2009), fato que foi verificado por Dias (2015) em alguns trabalhos acadêmicos analisados e por Valenti et al. (2012) nas UCs estudadas pelos autores. Apesar de constatada a predominância da adoção da linha pedagógica crítica, Valenti et al. (2012) notaram que as atividades realizadas nas UCs não eram compatíveis com os objetivos dispostos, ou mesmo não eram citadas atividades específicas para atingi-los. Tal fato também pôde ser constatado nos Parques analisados pelo presente trabalho, pois todas os Planos de Manejo com tendência político-pedagógica crítica também apresentaram elementos de outras tendências. Mais especificamente, Campina do Encantado, Cantareira, Ilhabela, Jaraguá e Serra do Mar exibiram as três macrotendências orientando suas ações de Educação Ambiental (FUNDAÇÃO FLORESTAL, 2008, 2008b, 2009, 2010a, 2015b). Essa incongruência é explicada por Carvalho (2006) pela existência do "nível da intenção" e do "nível da ação" em Educação Ambiental.

A maioria dos Planos de Manejo avaliados que empregou elementos da tendência crítica elenca ações basicamente de cunho conservacionista. É comum os Parques utilizarem elementos da tendência crítica como princípios a serem seguidos, mas fornecer uma lista de atividades que enfatiza o manejo das trilhas, o fortalecimento do ecoturismo, as palestras informativas, a coleta de resíduos, exposições, oficinas de arte e reciclagem, atividades lúdicas infantis, dentre outras, tal como ocorre nos Parques Cantareira e Serra do Mar (FUNDAÇÃO FLORESTAL, 2008c, 2009a). Em alguns casos, o Plano de Manejo destaca a importância de programas com cunho crítico, mas esclarece que estes precisam ser planejados, como foi verificado no Parque Intervales (FUNDAÇÃO FLORESTAL, 2009b).

Um exemplo claro dessa incongruência entre referencial teórico e ação foi constatada no Plano de Manejo do Parque Campina do Encantado, que desenvolve projetos típicos da tendência pragmática, como 0 Jovens ECOnscientes do Instituto Elektro, braço de uma companhia distribuidora de energia (FUNDAÇÃO FLORESTAL, 2008a). Esse projeto visa exercitar o programa de responsabilidade socioambiental da empresa, tendo como Revbea, São Paulo, V. 13, № 1: 192-212, 2018. 
objetivo formar lideranças para disseminar os conceitos de sustentabilidade. Nesse sentido, pode-se verificar que a tendência político-pedagógica crítica ainda se encontra no "nível da intenção" (CARVALHO, 2006), pois apesar de apresentar objetivos de tendência crítica para o programa de Educação Ambiental na UC, o projeto ECOnscientes em execução alinha-se a uma orientação pedagógica pragmática.

Também foi verificado que alguns Planos de Manejo utilizam conceitos tipicamente oriundos da tendência crítica, mas desprovidos do seu real sentido, como se pode verificar pelo seguinte trecho do Plano de Manejo do Parque Estadual Xixová-Japuí (FUNDAÇÃO FLORESTAL, 2010d, p.374):

A Educação Ambiental tranversalizada e emancipadora, entendida como uma estratégia de informação e formação que permeia todas as áreas de conhecimento, cumpre um papel ampliado nas unidades de conservação, uma vez que tendem a diminuir os conflitos existentes entre as comunidades e a áreas naturais protegidas a partir do momento que as pessoas conhecem e entendem o meio natural e desenvolvem uma noção de co-responsabilidade sobre este.

Nesse excerto, pode-se verificar uma deturpação do caráter emancipador e transversal da Educação Ambiental crítica, visto que o Plano a caracteriza como um instrumento para reverter o quadro da desinformação das pessoas com relação à conservação, ou seja, visa sensibilizar e promover a mudança de comportamento. Como já discutido anteriormente, essa concepção de Educação Ambiental é conservadora e muito característica da tendência conservacionista (LAYRARGUES; LIMA, 2009).

Em suma, em se tratando de uma Educação Ambiental com atividades basicamente de cunho conservador, Witt et al. (2013, p.95) proveem a seguinte reflexão acerca do delineamento do processo educativo em UCs pelos planejadores:

Até que ponto essas ações contribuem efetivamente para processos de conscientização ambiental? Até que ponto instigam a criticidade e apontam para práticas transformadoras da realidade? Ao proporem e enfatizarem somente a contemplação e a vivência por ela mesma, não estariam contribuindo para uma alienação das dinâmicas - sociais, políticas, culturais - que conformam o atual quadro da questão ambiental? E em que medida estimulam o desenvolvimento da práxis necessária para promover mudanças no atual quadro ambiental? 


\section{Considerações finais}

Uma vez identificada a lacuna sobre as tendências pedagógicas desenvolvidas em espaços públicos não formais de Educação Ambiental, foi possível contribuir com um diagnóstico do planejamento educativo dos Parques Estaduais de São Paulo, que são áreas protegidas aptas a receber essas atividades.

Todas as três macrotendências político-pedagógicas sintetizadas por Layrargues e Lima (2014) foram identificadas nos Planos de Manejo analisados, em conjunto ou isoladamente, sendo que a conservacionista foi detectada em toda a amostra. Esse resultado pode ser justificado pelo fato dessas áreas serem UCs de Proteção Integral, que abrigam ecossistemas naturais comumente propícios à contemplação paisagística e atividades de contato com o ambiente natural. Portanto, era esperada uma maior ênfase nas ações de sensibilização e proteção da natureza voltadas para a conservação, ecoturismo e atividades ao ar livre. A tendência pragmática, cujo caráter é conservador por não questionar o status quo, foi identificada em $56,25 \%$ dos Parques, por meio de atividades educativas de resolução de problemas ambientais dentro do que é permitido pelo sistema vigente, focando no desenvolvimento e consumo sustentável. Com relação à tendência crítica, $50 \%$ dos Planos de Manejo dos Parques empregaram seus elementos característicos.

Os resultados indicam uma influência profunda da corrente conservacionista nas ações de Educação Ambiental dos Parques paulistas. Por outro lado, verifica-se uma expansão da corrente crítica nessas áreas, o que tem sido verificado por outros autores. Entretanto, apesar do destaque dado a essa tendência alternativa, verifica-se que sua influência ainda está restrita ao "nível da intenção", não tendo ainda atingido o "nível da ação" (CARVALHO, 2006). Portanto, os Parques têm disposto objetivos e diretrizes críticas, mas a educação na prática se restringe basicamente a temas e atividades típicos das tendências conservadoras, em especial a conservacionista.

É importante destacar que os resultados apresentados se referem ao planejado pelos Parques, com informações extraídas de documentos oficiais abertos ao público. Assim, métodos alternativos como observação e entrevistas podem trazer um quadro distinto do obtido neste trabalho.

Finalmente, espera-se que a contribuição provida contribua para a reflexão sobre qual Educação Ambiental deve ser executada no âmbito dos espaços públicos, especialmente as Unidades de Conservação. Aqui, defendese a ideia de que esses espaços são extremamente relevantes e têm o potencial para desenvolver um processo educativo alternativo, emancipador e problematizador. Nesse sentido, ainda são necessários mais esforços para concretizar esse objetivo, visto que a corrente crítica deve ter maior influência na Educação Ambiental no âmbito desses espaços protegidos. 


\section{Referências}

AVANZI, M.R.; CARVALHO, I.C M.; FERRARO JR, L.A. Um olhar para a produção de pesquisa em Educação Ambiental a partir do GT Ambiente, Sociedade e Educação, da ANPPAS. Pesquisa em Educação Ambiental, v. 4, n. 2, p. 79-93, 2009.

BERTOLUCCI, D.; MACHADO, J.; SANTANA, L.C. Educação Ambiental ou educações ambientais? As adjetivações da Educação Ambiental brasileira. Revista Eletrônica do Mestrado em Educação Ambiental, Rio Claro, v. 15, n. 0, p.36-48, dez. 2005.

BRASIL. Constituição (1988). Constituição da República Federativa do Brasil. 1988. Disponível em: $<$ http://www.planalto.gov.br/ccivil 03/constituicao/constituicao.htm>. Acesso em: 01 mai. 2017.

BRASIL. Decreto no 5.758, de 13 de abril de 2006. Institui o Plano Estratégico Nacional de Áreas Protegidas - PNAP, seus princípios, diretrizes, objetivos e estratégias, e dá outras providências. 2006. Disponível em: $<$ http://www.planalto.gov.br/ccivil 03/ ato2004-2006/2006/decreto/d5758.htm>. Acesso em: 02 mai. 2017.

BRASIL. Lei no 9.795, de 27 de abril de 1999. Dispõe sobre a Educação Ambiental, institui a Política Nacional de Educação Ambiental e dá outras providências. $1999 . \quad$ Disponível em: $<$ http://www.planalto.gov.br/ccivil 03/leis/L9795.htm>. Acesso em: 01 mai. 2017.

BRASIL. Lei no 9.985, de 18 de julho de 2000. Institui o Sistema Nacional de Unidades de Conservação e dá outras providências. 2000. Disponível em: $<$ http://www.planalto.gov.br/ccivil 03/leis/L9985.htm>. Acesso em: 02 mai. 2017.

CARVALHO, L. M. A Temática Ambiental e o Processo Educativo: dimensões e abordagens. In: CINQÜETTI, H.; LOGAREZZI, A. (Orgs.). Resíduos sólidos e a Educação Ambiental. São Carlos: Ed UFSCar. 2006. p. 19-41.

DIAS, C.M. Práticas pedagógicas de Educação Ambiental em áreas protegidas: um estudo a partir de dissertações e teses (1981-2009). 2015. 208 p. Tese (Doutorado em Ensino de Ciências e Matemática) - Faculdade de Educação, Universidade Estadual de Campinas, Campinas, 2015.

FUNDAÇÃO FLORESTAL. Educação Ambiental. 2017a. Disponível em: $<$ http://fflorestal.sp.gov.br/educacao-ambiental/educacao-ambiental-conceito/>. Acesso em: 02 mai. 2017.

FUNDAÇÃO FLORESTAL. Parques estaduais. 2017b. Disponível em: <http://fflorestal.sp.gov.br/unidades-de-conservacao/parques-estaduais/>. Acesso em: 02 mai. 2017.

revista brasileira educação ambiental 
FUNDAÇÃO FLORESTAL. Plano de Manejo do Parque Estadual Campina do Encantado. Documento Técnico. 2008a. Disponível em: $<$ http://fflorestal.sp.gov.br/planos-de-manejo/planos-de-manejo-planosconcluidos/plano-de-manejo-pe-campina-do-encantado/>. Acesso em: 15 mai. 2017.

FUNDAÇÃO FLORESTAL. Plano de Manejo do Parque Estadual Campos do Jordão. Documento Técnico. 2015a. Disponível em: $<$ http://fflorestal.sp.gov.br/planos-de-manejo/planos-de-manejo-planosconcluidos/planos-de-manejo-pe-de-campos-do-jordao/>. Acesso em: 17 mai. 2017.

FUNDAÇÃO FLORESTAL. Plano de Manejo do Parque Estadual Cantareira. Documento Técnico. 2009a. Disponível em: <http://fflorestal.sp.gov.br/planosde-manejo/planos-de-manejo-planos-concluidos/plano-de-manejo-pe-dacantareira/>. Acesso em: 17 mai. 2017.

FUNDAÇÃO FLORESTAL. Plano de Manejo do Parque Estadual Carlos Botelho. Documento Técnico. 2008b. Disponível em: $<$ http://fflorestal.sp.gov.br/planos-de-manejo/planos-de-manejo-planosconcluidos/plano-de-manejo-pe-carlos-botelho/>. Acesso em: 17 mai. 2017.

FUNDAÇÃO FLORESTAL. Plano de Manejo do Parque Estadual dos Mananciais de Campos do Jordão. Documento Técnico. 2015b. Disponível em: $\quad<$ http://fflorestal.sp.gov.br/planos-de-manejo/planos-de-manejo-planosconcluidos/plano-de-manejo-pe-dos-mananciais-de-campos-do-jordao/>.

Acesso em: 17 mai. 2017.

FUNDAÇÃO FLORESTAL. Plano de Manejo do Parque Estadual Ilhabela. Documento Técnico. 2015c. Disponível em: <http://fflorestal.sp.gov.br/planosde-manejo/planos-de-manejo-planos-concluidos/plano-de-manejo-peilhabela/>. Acesso em: 17 mai. 2017.

FUNDAÇÃO FLORESTAL. Plano de Manejo do Parque Estadual Intervales. Documento Técnico. 2009b. Disponível em: <http://fflorestal.sp.gov.br/planosde-manejo/planos-de-manejo-planos-concluidos/plano-de-manejo-peintervales/>. Acesso em: 16 mai. 2017.

FUNDAÇÃO FLORESTAL. Plano de Manejo do Parque Estadual Jaraguá. Documento Técnico. 2010b. Disponível em: <http://fflorestal.sp.gov.br/planosde-manejo/planos-de-manejo-planos-concluidos/plano-de-manejo-pe-dojaragua/>. Acesso em: 16 mai. 2017.

FUNDAÇÃO FLORESTAL. Plano de Manejo do Parque Estadual Morro do Diabo. Documento Técnico. 2006. Disponível em: $<$ http://fflorestal.sp.gov.br/planos-de-manejo/planos-de-manejo-planosconcluidos/plano-de-manejo-pe-morro-do-diabo/>. Acesso em: 17 mai. 2017. 
FUNDAÇÃO FLORESTAL. Plano de Manejo do Parque Estadual Porto Ferreira. Documento Técnico. 2003. Disponível em: $<$ http://fflorestal.sp.gov.br/planos-de-manejo/planos-de-manejo-planosconcluidos/plano-de-manejo-pe-porto-ferreira/>. Acesso em: 17 mai. 2017.

FUNDAÇÃO FLORESTAL. Plano de Manejo do Parque Estadual Rio do Peixe. Documento Técnico. 2009c. Disponível em: $<$ http://fflorestal.sp.gov.br/planos-de-manejo/planos-de-manejo-planosconcluidos/plano-de-manejo-pe-do-rio-do-peixe/>. Acesso em: 17 mai. 2017.

FUNDAÇÃO FLORESTAL. Plano de Manejo do Parque Estadual Serra do Mar. Documento Técnico. 2008c. Disponível em: $<$ http://fflorestal.sp.gov.br/planos-de-manejo/planos-de-manejo-planosconcluidos/plano-de-manejo-pe-serra-do-mar/>. Acesso em: 17 mai. 2017.

FUNDAÇÃO FLORESTAL. Plano de Manejo do Parque Estadual Aguapeí. Documento Técnico. 2010a. Disponível em: <http://fflorestal.sp.gov.br/planosde-manejo/planos-de-manejo-planos-concluidos/plano-de-manejo-pe-doaguapei/>. Acesso em: 26 abr. 2017.

FUNDAÇÃO FLORESTAL. Plano de Manejo do Parque Estadual Jurupará. Documento Técnico. 2010c. Disponível em: <http://fflorestal.sp.gov.br/planosde-manejo/planos-de-manejo-planos-concluidos/plano-de-manejo-pe-dojurupara/>. Acesso em: 17 mai. 2017.

FUNDAÇÃO FLORESTAL. Plano de Manejo do Parque Estadual XixováJapuí. Documento Técnico. 2010d. Disponível em: $<$ http://fflorestal.sp.gov.br/planos-de-manejo/planos-de-manejo-planosconcluidos/plano-de-manejo-pe-xixova-japui/>. Acesso em: 17 mai. 2017.

FUNDAÇÃO FLORESTAL. Plano de Manejo do Parque Estadual Ilha do Cardoso. Documento Técnico. 2001. Disponível em: $<$ http://fflorestal.sp.gov.br/planos-de-manejo/planos-de-manejo-planosconcluidos/plano-de-manejo-pe-ilha-do-cardoso/>. Acesso em: 16 mai. 2017.

GIL, A.C. Métodos e técnicas de pesquisa social. 6 ed. São Paulo: Atlas, 2011. 200p.

LAYRARGUES, P.P.; LIMA, G.F.C. As macrotendências político-pedagógicas da Educação Ambiental brasileira. Ambiente \& Sociedade, v. 17, n. 1, p. 2340, mar. 2014.

LIMA, G.F.C. Educação Ambiental crítica: do socioambientalismo às sociedades sustentáveis. Educação e Pesquisa, v.35, n.1, p. 145-163, jan./abr. 2009.

LOUREIRO, C.F.B.; CUNHA, C.C. Educação Ambiental e gestão participativa de unidades de conservação: elementos para se pensar a sustentabilidade democrática. Ambiente \& Sociedade, v. 11, n. 2, p. 237-253, 2008. 
SÃO PAULO (Estado). Lei no 12.780, de 30 de novembro de 2007. Institui a Política Estadual de Educação Ambiental. 2007. Disponível em: <https://www.al.sp.gov.br/norma/?id=74690>. Acesso em: 25 mai. 2017.

SAUVÉ, L. Uma cartografia das correntes em Educação Ambiental. In: SATO, M.; CARVALHO, I. C. M. (Orgs.). Educação Ambiental - pesquisas e desafios. Porto Alegre: Artmed, 2005.

SORRENTINO, M. Vinte anos de Tbilisi, cinco da Rio 92: A Educação Ambiental no Brasil. Debates Socioambientais, São Paulo, CEDEC, ano II, n. 7, p. 3-5, jun/jul/ago/set 1997.

SOUZA, D.C; SAUVI, R.F.; A pesquisa em Educação Ambiental: um panorama sobre sua construção. Revista Ensaio, v.14, n. 3, p. 111-129, set-dez, 2012.

STAPP, W.B. The Concept of Environmental Education. Environmental Education, v. 1, n. 1, p. 30-31, 1 set. 1969.

VALENTI, M.W.; OLIVEIRA, H.T.; DODONOV; P.; SILVA, M.M. Educação Ambiental em unidades de conservação: políticas públicas e a prática educativa. Educação em Revista, v.28, n.1, p. 267-288, mar. 2012

WICK, M.A.L; SILVA, L.F. Unidades de conservação e processos em Educação Ambiental. REVBEA, São Paulo, v. 10, n 1, p. 201-220, 2015.

WITT, J.R.; LOUREIRO, C.F.B.; ANELLO, L.F.S. Vivências em Educação Ambiental em unidades de conservação: caminhantes na trilha da mudança. Revista Eletrônica Mestrado em Educação Ambiental. v. 30, n. 1, p. 83101, jan/jun. 2013. 